\title{
A Stochastic Model for Sediment Yield Using the Principle of Maximum Entropy
}

\author{
V. P. Singh AND P. F. Krstanovic \\ Department of Civil Engineering, Louisiana State University, Baton Rouge
}

\begin{abstract}
The principle of maximum entropy was applied to derive a stochastic model for sediment yield from upland watersheds. By maximizing the conditional entropy subject to certain constraints, a probability distribution of sediment yield conditioned on the probability distribution of direct runoff volume was obtained. This distribution resulted in minimally prejudiced assignment of probabilities on the basis of given information. The parameters of this distribution were determined from such prior information about the direct runoff volume and sediment yield as their means and covariance. The stochastic model was verified by using three sets of field data and was compared with a bivariate normal distribution. The model yielded sediment yield reasonably accurately.
\end{abstract}

\section{INTRODUCTION}

The total sediment outflow from a watershed, measurable at a point of reference spatially and in a specified period of time, is called sediment yield [American Society of Civil Engineers, 1970]. Its prediction is required for solution of a number of water resources problems. Determination of water quality in streams and reservoirs, transport of pollutants, undertaking cleanup following floods, protection of fish and wildlife habitats, development of opportunities for water-based sports and recreation, design of hydraulic works such as dams, debris basins and canals, design of soil conservation practices, planning urban works, evaluating the effects of certain land management practices, off-site damage evaluation, and cost evaluation of a water project are some of the examples. Sediment is a pollutant or a carrier of such pollutants as radioactive material, pesticides, and nutrients. Increased awareness of environmental quality and the desire to control nonpoint source pollution have significantly increased the need to estimate sediment yield. These applications may require mean value as well as variability of sediment yield corresponding to a given time interval (e.g., storm duration, daily, weekly, monthly, or yearly).

Many sediment yield models have been developed to address the aforementioned wide-ranging soil and water resources problems. Several reviews and discussions on various phases of sediment yield modeling have recently appeared in hydrologic literature. Foster [1981] made a comprehensive review of erosion process modeling. Renard [1977, 1980] reviewed the available techniques for estimating erosion rates, as well as discussed erosion and sediment yield modeling from rangeland. Woolhiser and Renard [1980] presented a discussion on stochastic aspects of sediment yield. Alonso [1980] evaluated a number of sediment transport formulas, bed load as well as total load. Williams [1982] provided a comprehensive survey of sediment yield modeling for erosion control, water resources planning, and water quality analysis. $\mathrm{Li}$ et al. [1973] reviewed a number of models for prediction of sediment yield from small watersheds. Knisel [1980a] provided an overview of erosion and sediment yield models. Singh [1986] has provided a comprehensive account of sediment yield models for upland areas.

Copyright 1987 by the American Geophysical Union.

Paper number 6W4348.

0043-1397/87/006W-4348\$05.00
The bulk of sediment yield models is deterministic which may be either empirical or conceptual. Some examples of empirical models [Agricultural Research Service, 1975] are sediment-rating curves, reservoir-sediment deposition surveys, sediment-delivery ratio, and bed load function extrapolation of measured records. These procedures require long data records so that time variability as well as annual yield of sediment can be determined. They usually link sediment yield to a rainfall-runoff relation [Rendon-Herrero, 1974, 1978; Williams 1978; Rendon-Herrero et al., 1980; Singh and Chen, 1982; Singh et al., 1982]. It has been empirically shown that sediment yield produced by a rainstorm is linearly correlated with the corresponding volume of the direct runoff on a log-log paper and that hydrographs of sediment discharge and corresponding runoff are similar in shape, have the same duration, and peak almost at the same time. Exploring these similarities further, Rendon-Herrero [1978] developed a so-called "unitsediment graph" concept which is analogous to the unithydrograph concept (e.g., standard unit of the sediment graph could be one ton, for a given duration, distributed over the watershed area). This concept is very simple to apply but has two main disadvantages: assumption of homogeneity in time and space (which is often not true), and requirement for continuous data sampling (which is often not met in practice).

Conceptual deterministic models have been developed by Foster and Meyer [1972, 1975], Smith [1976], Curtis [1976], Borah [1979], Li [1979], Ross et al. [1980], Knisel [1980b], Singh and Regl [1983], Singh and Prasad [1982], and Singh [1983], to name but a few. These models employ mechanics of sediment transport in a simplified form as for example kinematic wave approximation or zero-inertia formulation. Although these models appear promising, they remain to be tested extensively and their parameters evaluated in a wide variety of situations before they can be accepted as working tools. Furthermore, quantitative relationships between land use changes and their effect on model construction and its parameters need to be developed.

Stochastic models of sediment yield are relatively few. A. Murota and M. Hashino (unpublished manuscript, 1971) developed a stochastic model for transported sediment for the Arita River in Japan which included a stochastic model for daily rainfall with seasonally varying parameters, a deterministic rainfall-runoff relation, and a deterministic runoffsediment relation. Lane and Renard [1972] used a stochastic model for an ephemeral watershed, where ephemeral flow was 


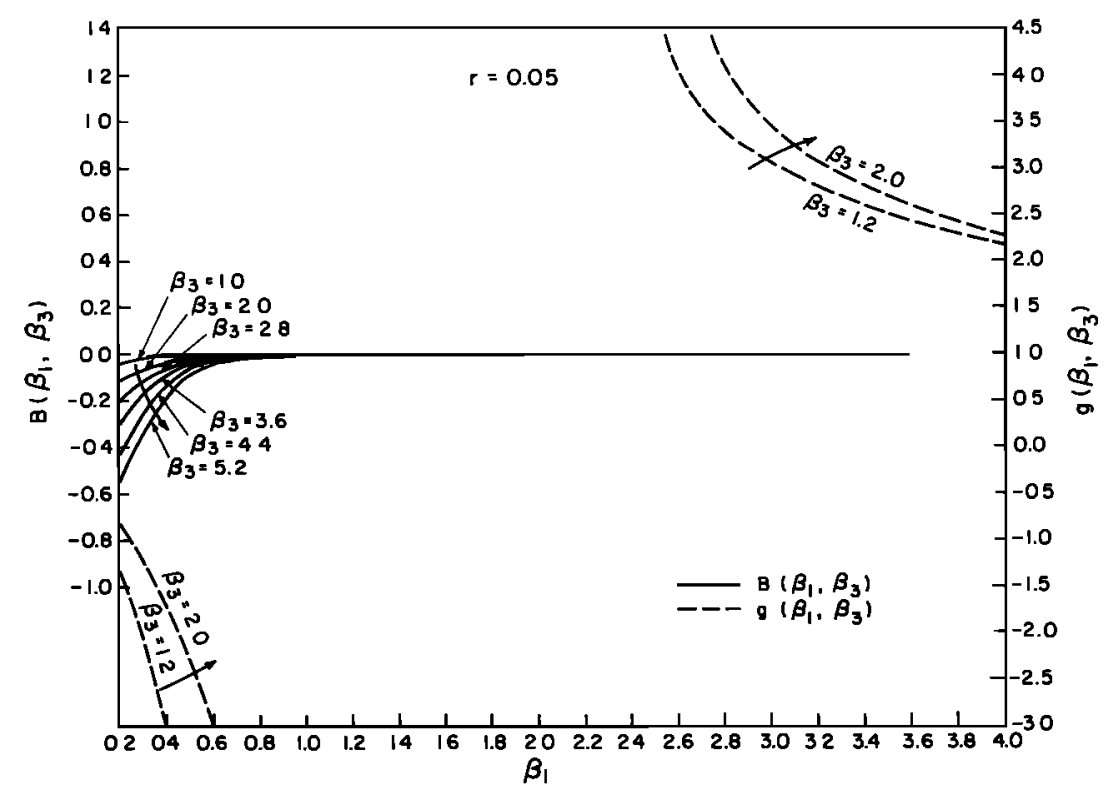

Fig. 1. Functions of $B\left(\beta_{1}, \beta_{3}\right)$ and $g\left(\beta_{1}, \beta_{3}\right)$ for various values of $\beta_{3}$ for $r=0.05$.

generated by a stochastic model on an event basis. Woolhiser and Todorovic [1974] and Woolhiser and Blinco [1975] developed probability distribution functions of sediment yield using the relationship between rainfall, runoff, and sediment yield. These stochastic models are constrained by the hypotheses regarding the processes of detachment, transport, and deposition of sediment and must be tested with field data. Sharma [1977] developed a discrete dynamic model for sediment yield using systems approach and logarithmic relationship between nonstationary runoff rate and sediment yield. By applying the transfer function plus noise models of the Box-Jenkins type, Caroni et al. [1984] developed two simple stochastic models for rainfall-runoff sediment yield relations. They, however, tested them on only one small watershed. All these models confirmed the main advantage of using a stochastic approach: possibility of generating long series of data by using statistical parameters based on a short sample.

This paper applied the principle of maximum entropy
(POME) to derive a probabilistic relationship between direct runoff volume (DR) and sediment yield (SY). The POME was used by Sonuga $[1972,1976]$ concerning rainfall-runoff relationship and hydrologic frequency analysis. Amorocho and Espildora [1973] used it to assess uncertainty in generation of streamflow by the Stanford Watershed Model. Singh et al. [1985] applied it to derive a number of frequency distributions used commonly in hydrology. A particular advantage of POME is that it is applicable where there are insufficient data. The stochastic model derived from POME was minimally prejudiced subject to given information. Three sets of field data were used to validate the model and then compared with a bivariate normal distribution.

\section{Principle of Maximum ENTROPY}

Entropy is defined as a measure of uncertainty or expectation of information. It was first applied in communication

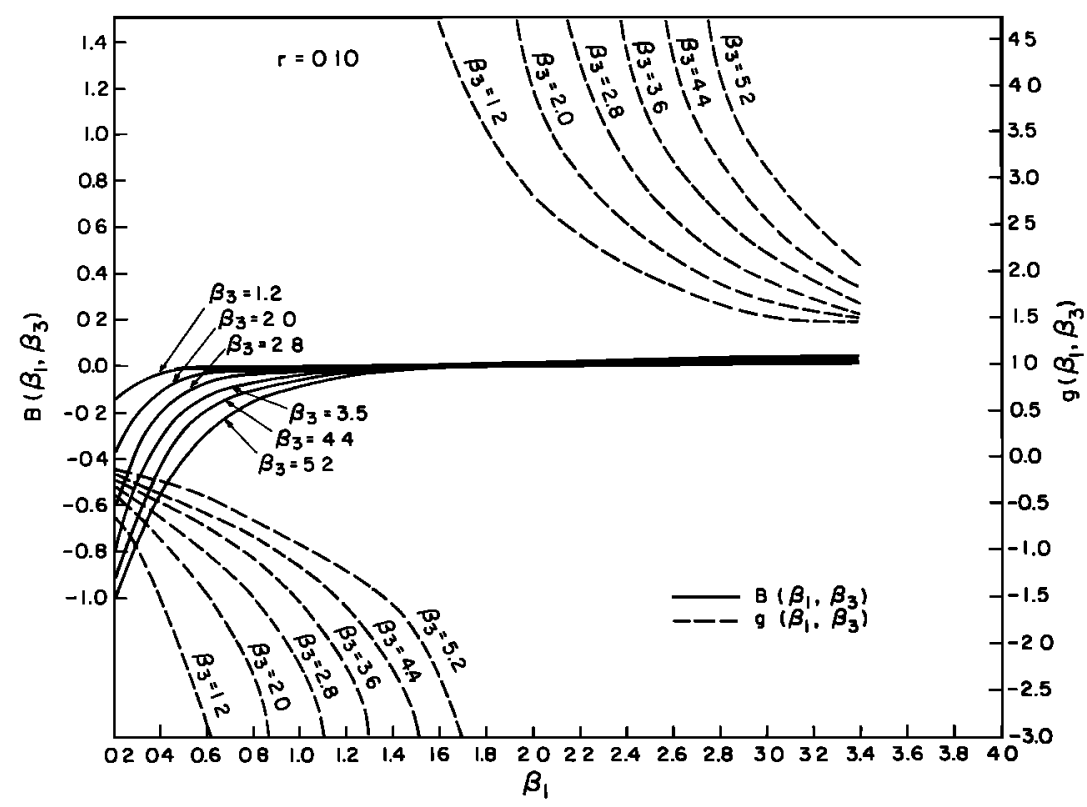

Fig. 2. Functions of $B\left(\beta_{1}, \beta_{3}\right)$ and $g\left(\beta_{1}, \beta_{3}\right)$ for various values of $\beta_{3}$ for $r=0.10$. 


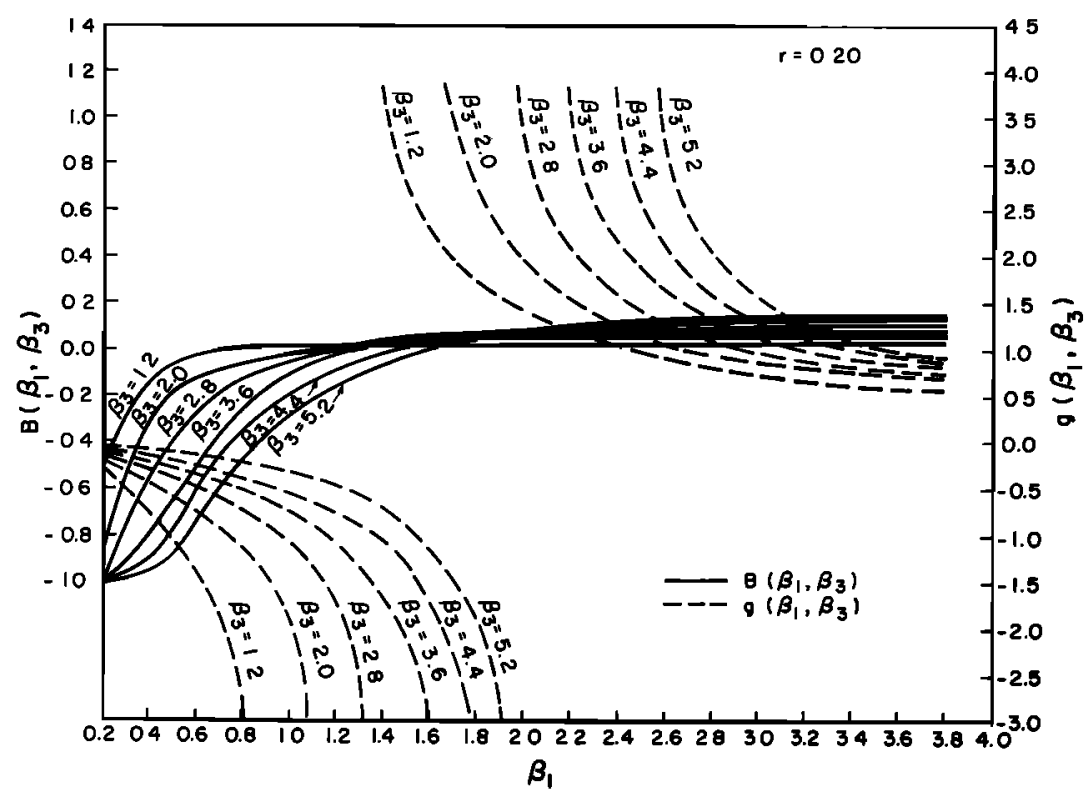

Fig. 3. Functions of $B\left(\beta_{1}, \beta_{3}\right)$ and $g\left(\beta_{1}, \beta_{3}\right)$ for various values of $\beta_{3}$ for $r=0.20$.

theory by Shannon and Weaver [1949] and has since been employed in virtually all engineering fields. If $x$ is a random variable, represented by a continuous distribution, then entropy is defined as

$$
H(x)=-K \int_{-\infty}^{+\infty} f(x) \log [f(x)] d x
$$

where $f(x)$ is probability density function (pdf), and $K$ is constant. From now onwards, $K$ will be absorbed in the base of the logarithm. Equation (1) includes a priori known probabilities due to our state of knowledge about the system. For a detailed discussion on entropy, the reader is referred to Shannon and Weaver [1949], Reza [1961], Jones [1979], and Wehrl [1978].

Jaynes $[1957 a, b]$ extended the concept of entropy by formulating the POME which says, "While making inferences based on incomplete information, draw them from the probability distribution that has the maximum entropy permitted by the known information." In most areas where POME has been applied, satisfactory results have been obtained in describing the processes where insufficient data exists. Therefore it is reasonable to extend this concept to develop a model for prediction of sediment yield especially when only a small amount of runoff data is available. That is, a minimally biased probability distribution appropriate for the runoff-sediment relationship can be developed.

In order to connect the pair of random variables $(x, y)$ through, joint entropy $H(x, y)$ is defined as

$$
H(x, y)=-\int_{-\infty}^{+\infty} \int_{-\infty}^{+\infty} f(x, y) \log f(x, y) d x d y
$$

where $f(x, y)$ is joint pdf for $x$ and $y$. Specifically, $x$ is runoff yield, and $y$ is sediment yield. By maximizing $H(x, y)$ subject to certain constraints, a minimally biased $f(x, y)$ can be obtained.

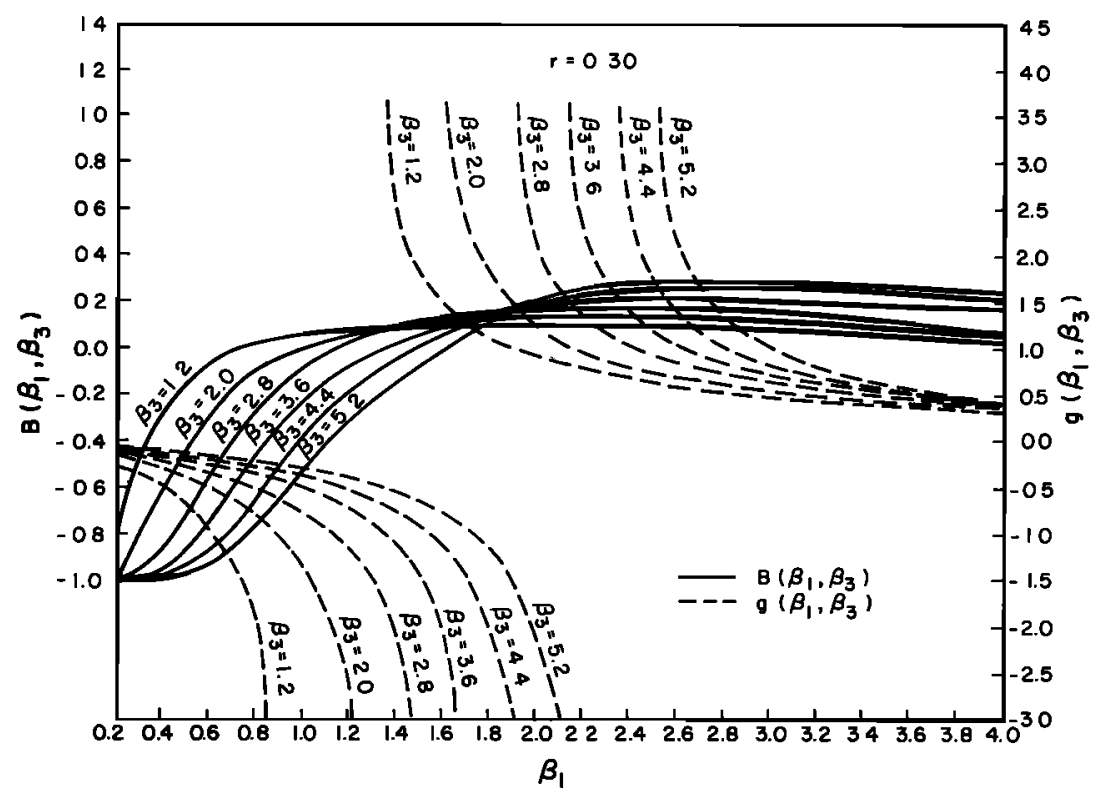

Fig. 4. Functions of $B\left(\beta_{1}, \beta_{3}\right)$ and $g\left(\beta_{1}, \beta_{3}\right)$ for various values of $\beta_{3}$ for $r=0.30$. 


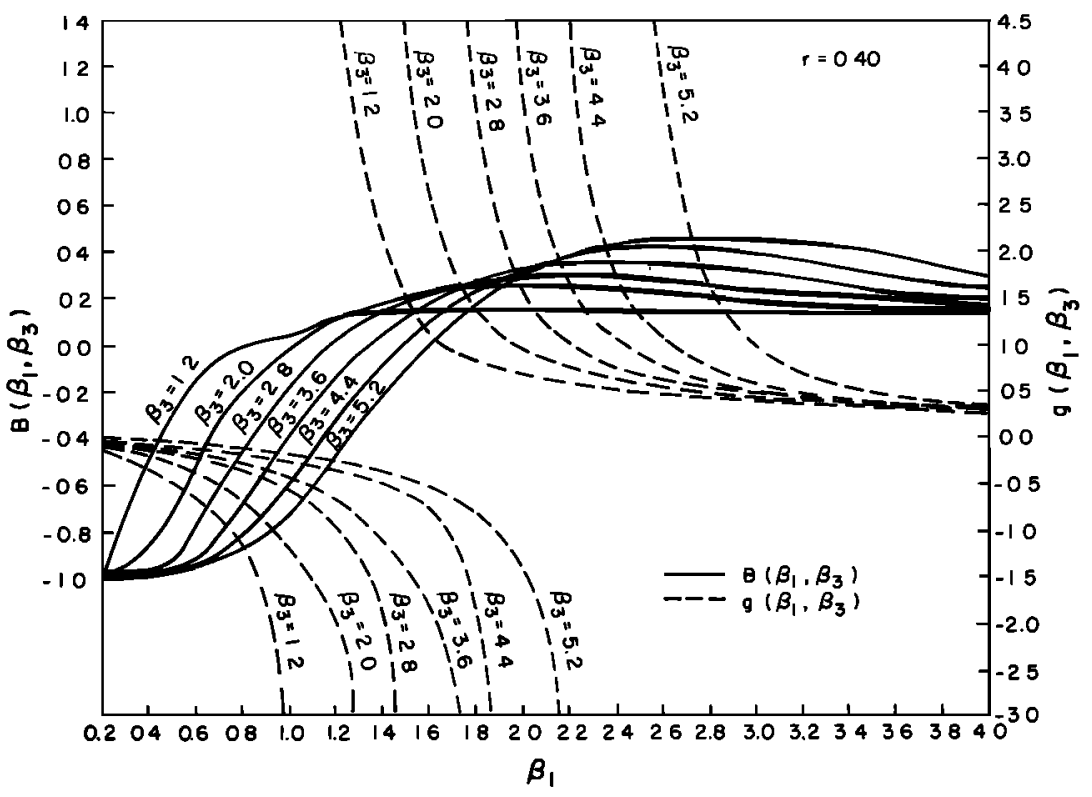

Fig. 5. Functions of $B\left(\beta_{1}, \beta_{3}\right)$ and $g\left(\beta_{1}, \beta_{3}\right)$ for various values of $\beta_{3}$ for $r=0.40$.

Derivation of a Stochastic Model for Sediment Yield

Our objective is to derive conditional pdf $f(y \mid x)$, which can be obtained from application of Bayes' theorem, provided $f(x, y)$ and $f(x)$ are known. To derive $f(x, y)$ we maximize $H(x, y)$, given by (2), subject to some specified constraints which were assumed as

$$
\begin{aligned}
\sigma_{x}^{2} & =\int_{-\infty}^{+\infty} \int_{-\infty}^{+\infty} f(x, y) x^{2} d x d y \\
\sigma_{y}{ }^{2} & =\int_{-\infty}^{+\infty} \int_{-\infty}^{+\infty} f(x, y) y^{2} d x d y \\
\sigma_{x y} & =\int_{-\infty}^{+\infty} \int_{-\infty}^{+\infty} f(x, y) x y d x d y \\
1 & =\int_{-\infty}^{+\infty} \int_{-\infty}^{+\infty} f(x, y) d x d y
\end{aligned}
$$

in which $\sigma_{w}{ }^{2}$ is variance of $w$, and $\sigma_{x y}$ is covariance of $x$ and $y$. In these equations, $x$ and $y$ are defined about their expected values; i.e., $x=x-E[x]$ and $y=y-E[y]$. Using the method of undertermined Lagrange multipliers $\lambda_{1}, \lambda_{2}, \lambda_{3}$, and $\lambda_{4}-1$, the unknown solution $f$ must satisfy [Reza, 1961, pp. 280-281]

$$
\frac{\partial}{\partial f}\left[-f \ln f+\lambda_{1}\left(f x^{2}\right)+\lambda_{2}\left(f y^{2}\right)+\lambda_{3}(f x y)+\lambda_{4}(f)\right]=0
$$

which yields

$$
-1-\ln f+\lambda_{1} x^{2}+\lambda_{2} y^{2}+\lambda_{3}(x y)+\lambda_{4}=0
$$

or

$$
f(x, y)=\exp \left[+\lambda_{1} x^{2}+\lambda_{2} y^{2}+\lambda_{3} x y+\lambda_{4}+1\right]
$$

$f(x, y)$ is the joint pdf of $(x, y)$ on the basis of the constraints imposed. Thus the problem reduces to determining $\lambda_{i}, i=1,2$,

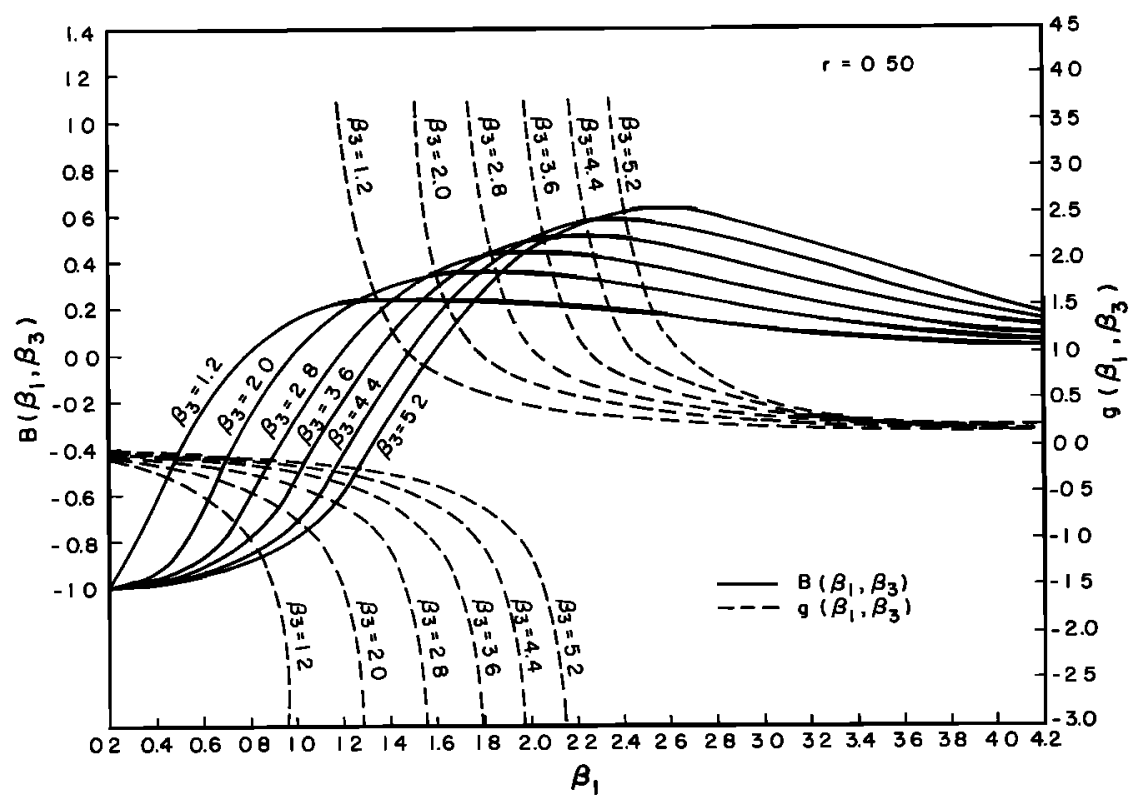

Fig. 6. Functions of $B\left(\beta_{1}, \beta_{3}\right)$ and $g\left(\beta_{1}, \beta_{3}\right)$ for various values of $\beta_{3}$ for $r=0.50$. 


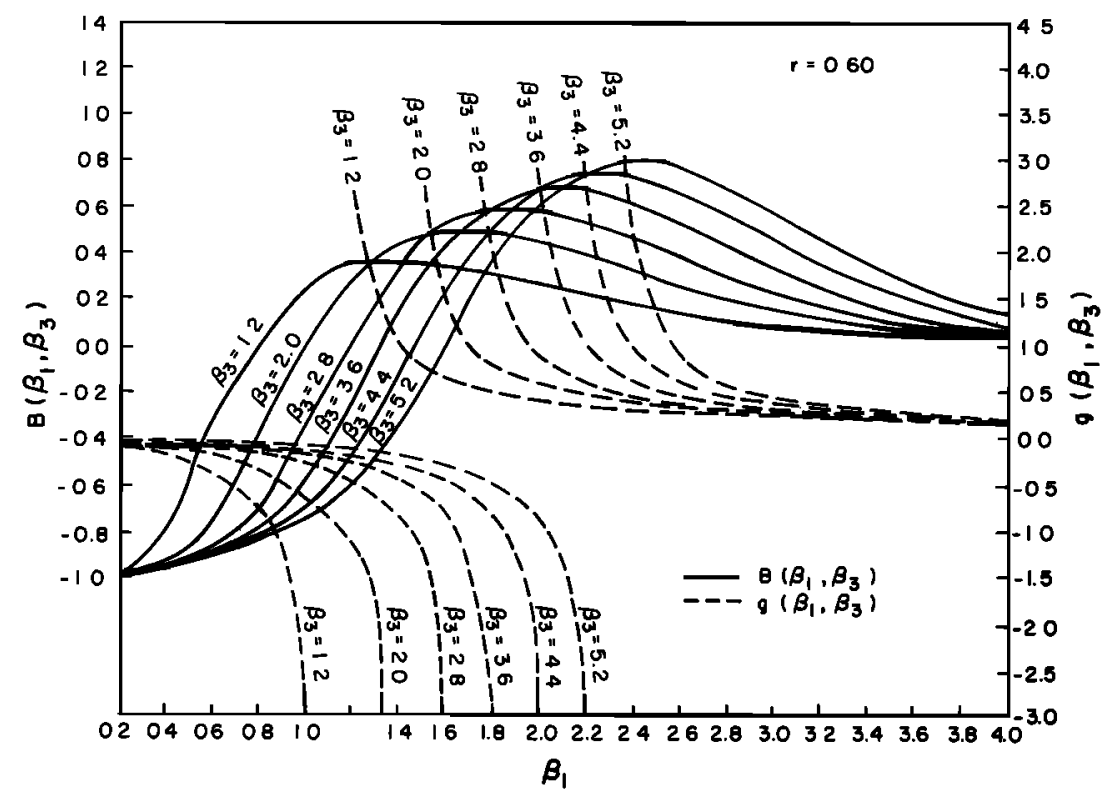

Fig. 7. Functions of $B\left(\beta_{1}, \beta_{3}\right)$ and $g\left(\beta_{1}, \beta_{3}\right)$ for various values of $\beta_{3}$ for $r=0.60$.

3,4 , subject to conditions in (3)-(6). Its solution is given in the appendix; only the final result is presented here.

We obtain four equations with four unknowns: (A1), (A5), (A7), and (A10) in the appendix. Rewriting them here,

$$
\begin{aligned}
\exp \left(\lambda_{4}\right) & =\frac{2 \pi}{\left(4 \lambda_{1} \lambda_{2}-\lambda_{3}{ }^{2}\right)^{1 / 2}} \\
\sigma_{x}{ }^{2} & =\frac{2 \lambda_{2}}{4 \lambda_{1} \lambda_{2}-\lambda_{3}{ }^{2}} \\
\sigma_{y}^{2} & =\frac{2 \lambda_{1}}{4 \lambda_{1} \lambda_{2}-\lambda_{3}{ }^{2}} \\
\sigma_{x y} & =-\frac{\lambda_{3}}{4 \lambda_{1} \lambda_{2}-\lambda_{3}^{2}}
\end{aligned}
$$

Multiplying (9) and (10) and subtracting the square of (11),

$$
\frac{4 \lambda_{1} \lambda_{2}}{\left(4 \lambda_{1} \lambda_{2}-\lambda_{3}{ }^{2}\right)^{2}}-\frac{\lambda_{3}{ }^{2}}{\left(4 \lambda_{1} \lambda_{2}-\lambda_{3}{ }^{2}\right)^{2}}=\frac{1}{4 \lambda_{1} \lambda_{2}-\lambda_{3}{ }^{2}}
$$

or

$$
\sigma_{x}^{2}{\sigma_{y}}^{2}-\sigma_{x y}^{2}=\frac{1}{4 \lambda_{1} \lambda_{2}-\lambda_{3}^{2}}
$$

Equation (8) can be written as

$$
\exp \left(\lambda_{4}\right)=(2 \pi)\left(\sigma_{x}{ }^{2} \sigma_{y}{ }^{2}-\sigma_{x y}{ }^{2}\right)^{1 / 2}
$$

By using (12) and (13), the unknowns $\lambda_{1}, \lambda_{2}, \lambda_{3}$, and $\lambda_{4}$ can be expressed with known quantities $\sigma_{x}{ }^{2}, \sigma_{y}{ }^{2}$, and $\sigma_{x y}$. Thus the maximum joint pdf in (7) can be written as

$$
f(x, y)=\exp \left(-\lambda_{4}\right) \exp \left(-\lambda_{1} x^{2}-\lambda_{2} y^{2}-\lambda_{3} x y\right)
$$

The terms in the second exponent can be obtained from (9),

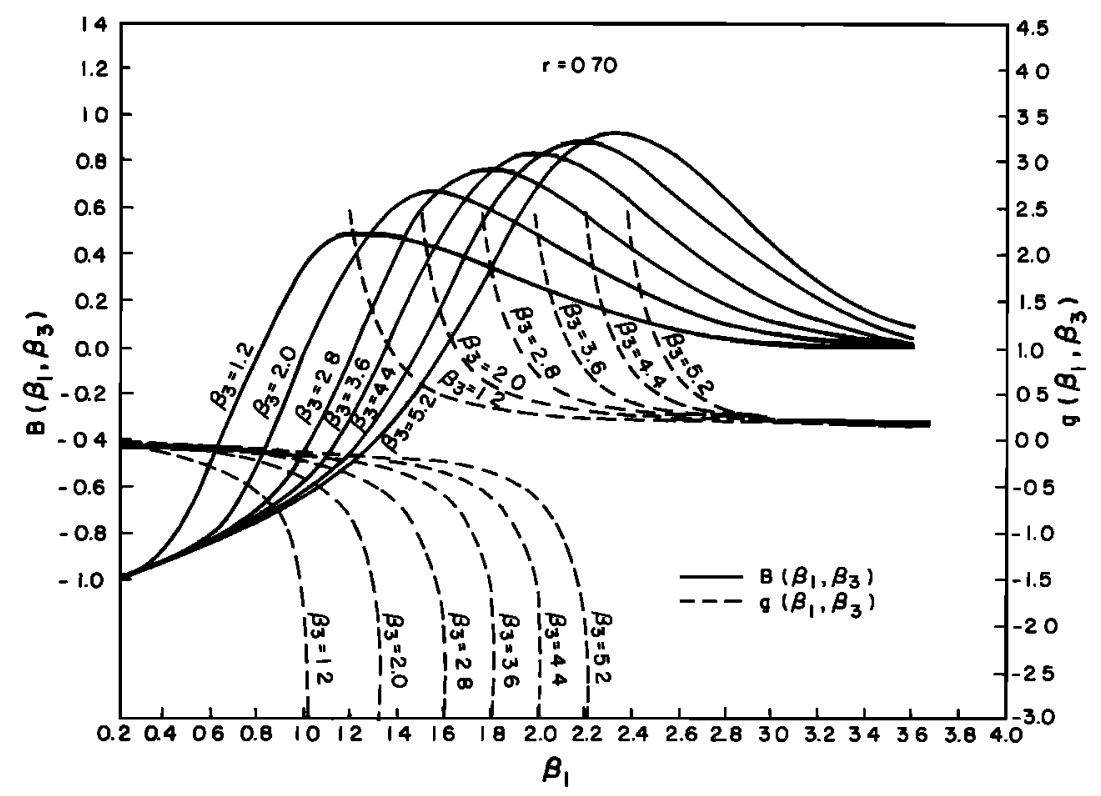

Fig. 8. Functions of $B\left(\beta_{1}, \beta_{3}\right)$ and $g\left(\beta_{1}, \beta_{3}\right)$ for various values of $\beta_{3}$ for $r=0.70$. 


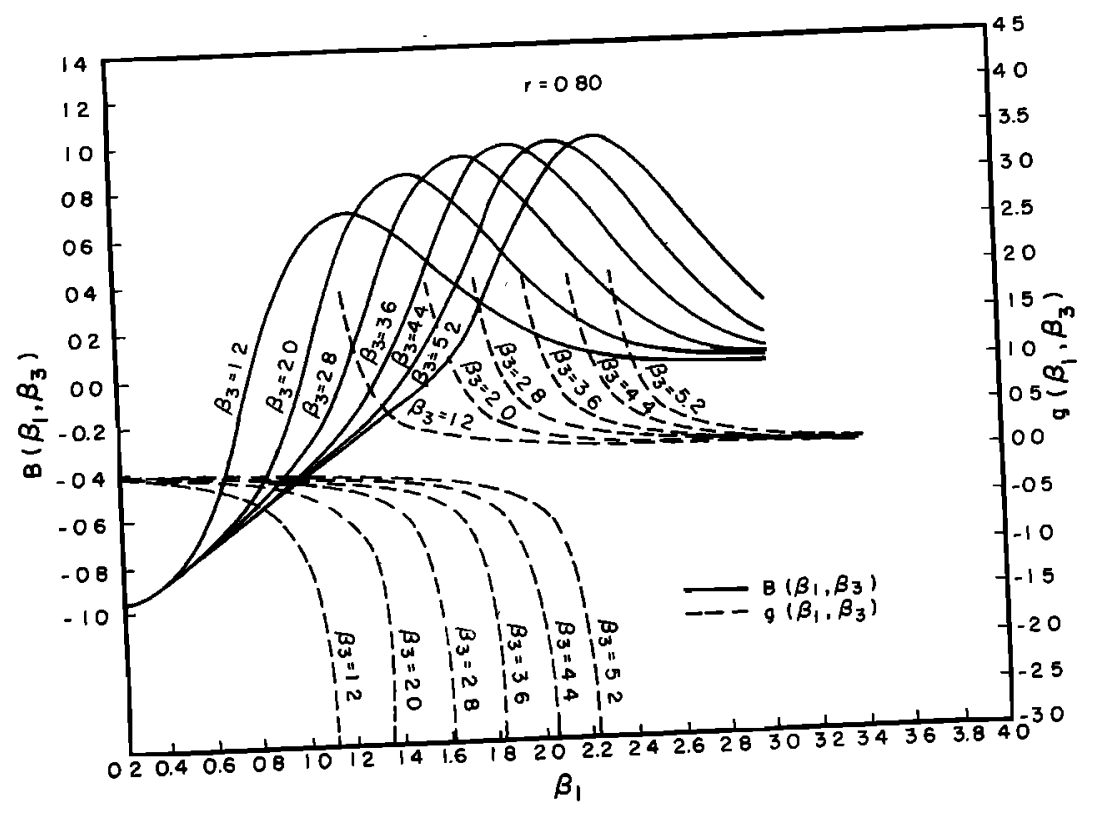

Fig. 9. Functions of $B\left(\beta_{1}, \beta_{3}\right)$ and $g\left(\beta_{1}, \beta_{3}\right)$ for various values of $\beta_{3}$ for $r=0.80$.

(10), and (11) as

$$
\begin{aligned}
& \lambda_{1} x^{2}=\frac{\sigma_{y}{ }^{2}}{2}\left(4 \lambda_{1} \lambda_{2}-\lambda_{3}{ }^{2}\right) x^{2}=\frac{\sigma_{x y}{ }^{2} x^{2}}{2} \frac{1}{\sigma_{x}{ }^{2} \sigma_{y}{ }^{2}-\sigma_{x y}{ }^{2}} \\
& \lambda_{2} y^{2}=\frac{\sigma_{x}{ }^{2}}{2}\left(4 \lambda_{1} \lambda_{2}-\lambda_{3}{ }^{2}\right) y^{2}=\frac{\sigma_{x}{ }^{2} y^{2}}{2} \frac{1}{\sigma_{x}{ }^{2} \sigma_{y}{ }^{2}-\sigma_{x y}{ }^{2}} \\
& \lambda_{3} x y=-\sigma_{x y} x y\left(4 \lambda_{1} \lambda_{2}-\lambda_{3}{ }^{2}\right)=-\frac{\sigma_{x y} x y}{\sigma_{x}{ }^{2} \sigma_{y}{ }^{2}-\sigma_{x y}{ }^{2}}
\end{aligned}
$$

respectively.

Finally, (14) can be written as

$$
\begin{aligned}
f(x, y)=\frac{1}{2 \pi\left(\sigma_{x}{ }^{2} \sigma_{y}{ }^{2}-\sigma_{x y}{ }^{2}\right)^{1 / 2}} \\
\cdot \exp \left\{-\frac{\left[\sigma_{x}{ }^{2} y^{2}+\sigma_{y}{ }^{2} x^{2}-2\left(\sigma_{x y}\right) x y\right]}{2\left(\sigma_{x}{ }^{2} \sigma_{y}{ }^{2}-\sigma_{y}{ }^{2}\right)}\right\}
\end{aligned}
$$

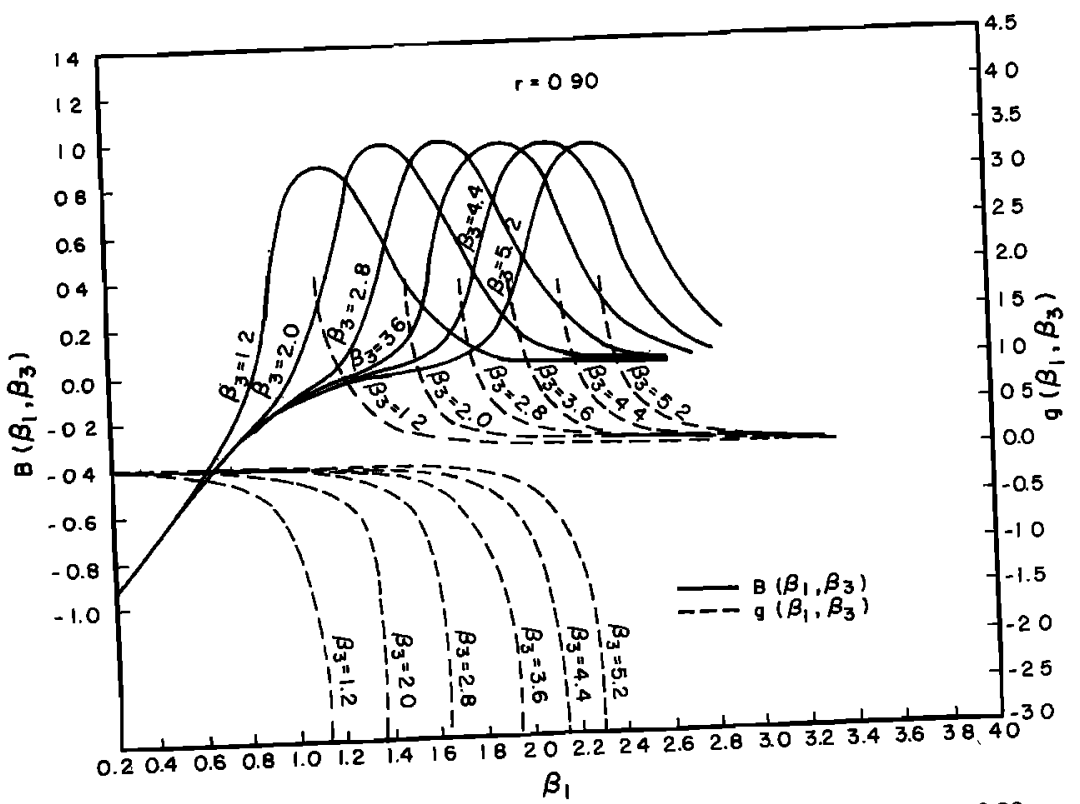

Fig. 10. Functions of $B\left(\beta_{1}, \beta_{3}\right)$ and $g\left(\beta_{1}, \beta_{3}\right)$ for various values of $\beta_{3}$ for $r=0.90$.
Equation (16) is the joint pdf of $(x, y)$ subject to the constraints (3) to (6) and also represents bivariate normal distribution of $x$

The marginal pdf $f(y)$ of sediment yield can be obtained from $f(x, y)$ simply by integrating joint pdf across $x$ domain, while keeping $y$ as constant. Similarly, $f(x)$ can be obtained:

$$
\begin{aligned}
& f(x)=\frac{1}{(2 \pi)^{1 / 2} \sigma_{x}} \exp \left(-\frac{x^{2}}{2 \sigma_{x}^{2}}\right) \\
& f(y)=\frac{1}{(2 \pi)^{1 / 2} \sigma_{x}} \exp \left(-\frac{y^{2}}{2 \sigma_{y}^{2}}\right)
\end{aligned}
$$

The conditional pdf of $y$ (sediment yield) due to the knowledge of $x$ (runoff) can be expressed as

$$
f(y \mid x)=\frac{f(x, y)}{f(x)}
$$



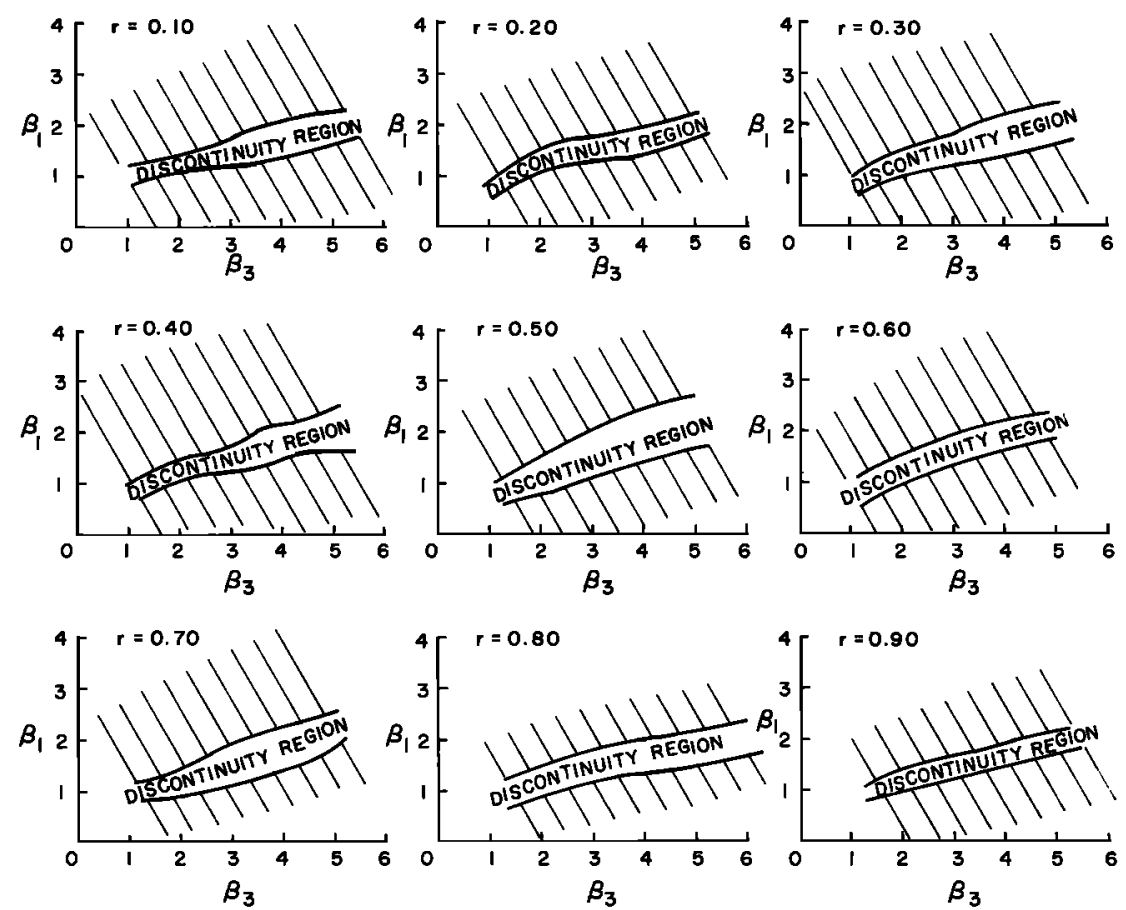

Fig. 11. Regions of validity of $\beta_{1}$ and $\beta_{3}$ for various values of $r$.

which produces after substitution of (17) and (18)

$$
\begin{aligned}
& f(y \mid x)=\frac{\sigma_{x}}{\left(2 \pi\left({\sigma_{x}}^{2}{\sigma_{y}}^{2}-{\sigma_{x y}}^{2}\right)\right)^{1 / 2}}
\end{aligned}
$$

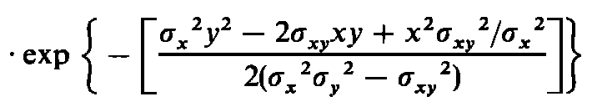

This expression is the pdf of $y$ conditional on $x$ and is the same as the conditional normal distribution with the mean values of $x$ and $y$ as zero. The cumulative density function (cdf) $F(y \mid x)$ can be obtained by integrating with respect to $y$,

$$
\begin{aligned}
F(y \mid x)= & \frac{\sigma_{x}}{\left(2 \pi\left(\sigma_{x}{ }^{2} \sigma_{y}{ }^{2}-{\sigma_{x y}}^{2}\right)\right)^{1 / 2}} \\
& \cdot \int_{-\infty}^{y} \exp \left\{-\frac{{\sigma_{x}}^{2}}{2\left({\sigma_{x}}^{2}{\sigma_{y}}^{2}-{\sigma_{x y}}^{2}\right)}\left[y-\left(\sigma_{x y} /{\sigma_{x}}^{2}\right) x\right]^{2}\right\} d y
\end{aligned}
$$

Making the substitutions

$$
\begin{gathered}
\frac{\sigma_{x}}{\left(2\left({\sigma_{x}}^{2}{\sigma_{y}}^{2}-{\sigma_{x y}}^{2}\right)\right)^{1 / 2}}=c_{1} \\
c_{1}\left(y-\left(\sigma_{x y} /{\sigma_{x}}^{2}\right) x\right)=z / \sqrt{2} \\
d y=d z / c_{1} \sqrt{2}
\end{gathered}
$$

$F(y \mid x)$ can be written as

$$
F(y \mid x)=\frac{1}{(2 \pi)^{1 / 2}} \int_{-\infty}^{\left(y-\left(\sigma_{x y} / \sigma_{x}^{2}\right) x\right) c_{1} \sqrt{2}} \exp \left(-z^{2} / 2\right) d z
$$

which is the integral form of the standard normal distribution. It must be mentioned that integration of $(20)$ is performed to obtain (22) for the general case from " $-\infty$ " to $y$, as from the beginning (constraint (6)) we are working on the entire probability space. However, for the sediment yield-runoff relationship, integration should start from the minimum observed value of the sediment yield (say, zero or some small value close to it) and will end with any $y \leq$ maximum (known from obser- vations or historical experience). In other words, we use truncated distribution $F_{t}(y \mid x)$ defined as

$$
F_{t}(y \mid x)=\frac{F(y \mid x)}{F\left(y_{\max } \mid x\right)-F(y=0 \mid x)}
$$

The numerator of (23) is simplified as

$$
F(y \mid x)=\frac{1}{2}\left\{\Phi\left[\left(x \sigma_{x y} / \sigma_{x}^{2}-y\right) c_{1}\right]-1\right\}
$$

where $\Phi$ stands for standard normal distribution. The denominator of (23) is solved as

$$
\begin{aligned}
F\left(y_{\max } \mid x\right)- & F(y=0 \mid x) \\
= & \frac{c_{1}}{\sqrt{\pi}} \int_{-\infty}^{y_{\max }} \exp \left[-{c_{1}}^{2}\left(y-\left(\sigma_{x y} /{\sigma_{x}}^{2}\right) x\right)^{2}\right] d y \\
& -\frac{c_{1}}{\sqrt{\pi}} \int_{-\infty}^{0} \exp \left[-c_{1}{ }^{2}\left(y-\left(\sigma_{x y} /{\sigma_{x}}^{2}\right) x\right)^{2}\right] d y
\end{aligned}
$$

Using the substitutions $Y=y-\left(\sigma_{x y} / \sigma_{x}^{2}\right) x$ in both integrals and integrating,

$$
\begin{aligned}
& F\left(y_{\max } \mid x\right)-F(y=0 \mid x) \\
& =\frac{c_{1}}{\sqrt{\pi}}\left[\frac{\sqrt{\pi}}{2 c_{1}}-\frac{\sqrt{\pi}}{2 c_{1}}\left(1-\Phi\left(\frac{\left(\sigma_{x y} / \sigma_{x}{ }^{2}\right) x-y_{\max }}{2\left(1 / 4 c_{1}{ }^{2}\right)^{1 / 2}}\right)\right)\right]
\end{aligned}
$$

On simplifying,

$$
F\left(y_{\max } \mid x\right)-F(y=0 \mid x)=\frac{1}{2} \Phi\left[c_{1}\left(\left(\sigma_{x y} / \sigma_{x}^{2}\right) x-y_{\max }\right)\right]
$$

Substituting (24) and (25) into (23),

$$
F_{t}(y \mid x)=\frac{\Phi\left[\left(x\left(\sigma_{x y} / \sigma_{x}^{2}\right)-y\right) c_{1}\right]-1}{\Phi\left[\left(x\left(\sigma_{x y} / \sigma_{x}^{2}\right)-y_{\max }\right) c_{1}\right]}
$$

For practical purposes, it may be desirable to express $F(y \mid x)$ in dimensionless form. This can be done by using beta coef- 
ficients [Yevjevich, 1972] defined as

$$
\beta_{1}=x / \sigma_{x} \quad \beta_{2}=y / \sigma_{y} \quad \beta_{3}=x y / \sigma_{x y}=\beta_{1} \beta_{2} / r
$$

where $r$ is correlation coefficient. We first transform the expression for conditional pdf (20) into dimensionless form and then integrate to obtain dimensionless distribution $F(y \mid x)$. From (20),

$$
\begin{aligned}
f(y \mid x)=\frac{\sigma_{x}}{\left(2 \pi\left(\sigma_{x}{ }^{2}{\sigma_{y}}^{2}-\sigma_{x y}{ }^{2}\right)\right)^{1 / 2}} \\
\cdot \exp \left\{-\left[\frac{\sigma_{x}{ }^{2} y^{2}+\sigma_{y}{ }^{2} x^{2}-2 \sigma_{x y} x y}{2\left(\sigma_{x}{ }^{2} \sigma_{y}{ }^{2}-\sigma_{x y}{ }^{2}\right)}-\frac{x^{2}}{2 \sigma_{x}{ }^{2}}\right]\right\}
\end{aligned}
$$

Simplifying the exponential term,

$$
\begin{aligned}
A= & \exp \left\{-\left[\frac{1 / \beta_{1}{ }^{2}+1 / \beta_{2}{ }^{2}-2 / \beta_{3}}{\left(2 / \beta_{1}{ }^{2}{\beta_{2}}^{2}\right)\left(1-r^{2}\right)}-\beta_{1}{ }^{2} / 2\right]\right\} \\
A= & \exp \left\{\frac{-{\beta_{2}}^{2}-{\beta_{1}}^{2}+2\left(\beta_{1}{ }^{2} \beta_{2}{ }^{2} / \beta_{3}\right)}{2\left(1-r^{2}\right)}+\beta_{1}{ }^{2} / 2\right\} \\
= & \exp \left\{\beta_{1}{ }^{2}\left(\frac{1}{2}-\frac{1}{2\left(1-r^{2}\right)}\right)\right\} \\
& \cdot \exp \left\{-\frac{\beta_{2}{ }^{2}}{2\left(1-r^{2}\right)}\left[1-\frac{2 \beta_{1}{ }^{2}}{\beta_{3}}\right]\right\}
\end{aligned}
$$

\begin{tabular}{|c|c|c|c|c|}
\hline \multirow[b]{2}{*}{ No. } & \multicolumn{2}{|c|}{ John Martin Reservoir } & \multicolumn{2}{|c|}{ Green River, Kentucky } \\
\hline & $\begin{array}{l}\text { Runoff } x \\
86,400 \mathrm{~m}^{3}\end{array}$ & $\begin{array}{c}\text { Sediment Yield } y \text {, } \\
\text { tons/daily }\end{array}$ & $\begin{array}{l}\text { Runoff } x \\
86,400 \mathrm{~m}^{3}\end{array}$ & $\begin{array}{l}\text { Sediment Yield } y \text {, } \\
\text { tons/daily }\end{array}$ \\
\hline 1 & 2.34 & 48.32 & 29.81 & 308.86 \\
\hline 2 & 2.35 & 52.76 & 38.23 & 746.89 \\
\hline 3 & 3.54 & 78.95 & 43.96 & 608.73 \\
\hline 4 & 4.20 & 109.17 & 48.96 & 832.37 \\
\hline 5 & 4.71 & 115.23 & 49.17 & 955.21 \\
\hline 6 & 4.72 & 127.36 & 49.63 & 977.50 \\
\hline 7 & 5.11 & 194.08 & 52.88 & 1038.06 \\
\hline 8 & 5.34 & 206.21 & 66.42 & 1128.28 \\
\hline 9 & 5.37 & 224.41 & 66.44 & 1169.83 \\
\hline 10 & 6.11 & 376.03 & 73.59 & 1177.57 \\
\hline 11 & 6.25 & 442.75 & 73.66 & 1298.04 \\
\hline 12 & 8.74 & 448.81 & 75.68 & 1353.51 \\
\hline 13 & 8.32 & 460.94 & 77.32 & 1359.34 \\
\hline 14 & 8.68 & 491.26 & 81.41 & 1368.58 \\
\hline 15 & 10.07 & 533.72 & 81.89 & 1478.47 \\
\hline 16 & 10.40 & 551.92 & 86.96 & 2016.80 \\
\hline 17 & 10.59 & 564.04 & 88.95 & 2039.48 \\
\hline 18 & 12.03 & 624.70 & 96.46 & 2113.78 \\
\hline 19 & 13.36 & 667.15 & 99.69 & 2272.21 \\
\hline 20 & 16.14 & 727.80 & 111.03 & 2575.96 \\
\hline 21 & 17.38 & 788.45 & 115.05 & 2933.93 \\
\hline 22 & 17.76 & 2304.70 & & \\
\hline 23 & 26.54 & 2426.00 & & \\
\hline \multicolumn{3}{|c|}{$\begin{array}{c}\sigma_{x}=5.93, \sigma_{y}=617.0 \\
\text { and } \sigma_{x y}=3265.0\end{array}$} & \multicolumn{2}{|c|}{$\begin{array}{c}\sigma_{x}=23.63, \sigma_{y}=673.0 \\
\text { and } \sigma_{x y}=15,293\end{array}$} \\
\hline
\end{tabular}

Now simplifying the term associated with the exponential part,

$$
c_{1}^{2}=\frac{\sigma_{x}^{2}}{2\left(\sigma_{x}{ }^{2}{\sigma_{y}}^{2}-{\sigma_{x y}}^{2}\right)}=\frac{\sigma_{x}^{2}}{2\left({\sigma_{x}}^{2}{\sigma_{y}}^{2}-r^{2}{\sigma_{x}}^{2}{\sigma_{y}}^{2}\right)}=\frac{1}{2{\sigma_{y}}^{2}\left(1-r^{2}\right)}
$$

TABLE 1. Runoff-Sediment Data

Data sets for the John Martin Reservoir and Green River, Kentucky are ordered according to the magnitude.
Inserting (28) and (29) in $f(y \mid x)$,

$$
\begin{aligned}
f(y \mid x)=\frac{\exp \left\{\beta_{1}{ }^{2}\left(\frac{1}{2}-\frac{1}{2\left(1-r^{2}\right)}\right)\right\}}{\left(2 \pi \sigma_{y}{ }^{2}\left(1-r^{2}\right)\right)^{1 / 2}} & \\
\cdot \exp \left\{-\frac{\beta_{2}{ }^{2}}{2\left(1-r^{2}\right)}\left[1-\frac{2 \beta_{1}{ }^{2}}{\beta_{3}}\right]\right\} &
\end{aligned}
$$

The cdf $F(y \mid x)$ can be obtained by integrating from 0 to $y$ with substitution $d y=d \beta_{2} \sigma_{y}$ :

$$
\begin{aligned}
& F(y \mid x)=\frac{\exp \left\{\beta_{1}{ }^{2}\left(\frac{1}{2}-\frac{1}{2\left(1-r^{2}\right)}\right)\right\}}{\left(2 \pi\left(1-r^{2}\right)\right)^{1 / 2}} \\
& \cdot \int_{0}^{\beta_{2}} \exp \left\{-\frac{\beta_{2}^{2}}{2\left(1-r^{2}\right)}\left[1-\frac{2 \beta_{1}{ }^{2}}{\beta_{3}}\right]\right\} d \beta_{2} \\
& =\frac{1}{\left(2 \pi\left(1-r^{2}\right)\right)^{1 / 2}} \exp \left\{\beta_{1}{ }^{2}\left(\frac{1}{2}-\frac{1}{2\left(1-r^{2}\right)}\right)\right\} \\
& \text {. } \int_{0}^{\beta_{2}} \exp \left\{-\beta_{2}{ }^{2}\left[\frac{\beta_{3}-2 \beta_{1}{ }^{2}}{2 \beta_{3}\left(1-r^{2}\right)}\right]\right\} d \beta_{2} \\
& F(y \mid x)=\frac{\exp \left\{\beta_{1}^{2}\left[\frac{1}{2}-\frac{1}{2\left(1-r^{2}\right)}\right]\right\}}{\left(2 \pi\left(1-r^{2}\right)\right)^{1 / 2}} \\
& \int_{0}^{\beta_{2}} \exp \left\{-\beta_{2}{ }^{2}\left[\frac{\frac{\beta_{1} \beta_{2}}{r}-2 \beta_{1}{ }^{2}}{2 \frac{\beta_{1} \beta_{2}}{r}\left(1-r^{2}\right)}\right]\right\} d \beta_{2}
\end{aligned}
$$

On simplifying,

$$
\begin{aligned}
F(y \mid x)=\frac{\exp \left\{\beta_{1}{ }^{2}\left[\frac{1}{2}-\frac{1}{2\left(1-r^{2}\right)}\right]\right\}}{\left(2 \pi\left(1-r^{2}\right)\right)^{1 / 2}} \\
\cdot \int_{0}^{\beta_{2}} \exp \left[-\frac{\beta_{2}^{2}}{2\left(1-r^{2}\right)}+\frac{\beta_{1} \beta_{2} r}{1-r^{2}}\right] d \beta_{2}
\end{aligned}
$$

and on integrating,

$$
\begin{aligned}
F(y \mid x) & =\left(\frac{1-r^{2}}{2 \pi}\right)^{1 / 2} \frac{\beta_{1}}{r\left(\beta_{1}{ }^{2}-\beta_{3}\right)} \\
\cdot & \left\{\exp \left[-\frac{\left(\beta_{1}-\beta_{3} / \beta_{1}\right)^{2}}{2\left(1 / r^{2}-1\right)}\right]-\exp \left[-\frac{\beta_{1}{ }^{2}}{2\left(1 / r^{2}-1\right)}\right]\right\}
\end{aligned}
$$

which can be written as

$$
F(y \mid x)=g\left(\beta_{1}, \beta_{3}\right) B\left(\beta_{1}, \beta_{3}\right)
$$

where

$$
\begin{gathered}
g\left(\beta_{1}, \beta_{3}\right)=\left(\frac{1-r^{2}}{2 \pi}\right)^{0.5} \frac{\beta_{1}}{r\left(\beta_{1}^{2}-\beta_{3}\right)} \\
B\left(\beta_{1}, \beta_{3}\right)=\exp \left[-\frac{\left(\beta_{1}-\beta_{3} / \beta_{1}\right)^{2}}{2\left(1 / r^{2}-1\right)}\right]-\exp \left[-\frac{\beta_{1}^{2}}{2\left(1 / r^{2}-1\right)}\right]
\end{gathered}
$$

The functions $B\left(\beta_{1}, \beta_{3}\right)$ and $g\left(\beta_{1}, \beta_{3}\right)$ are plotted against $\beta_{1}$ for various values of $\beta_{3}$ and correlation coefficient $r$ as shown in Figures 1-10. The regions of validity of functions $B\left(\beta_{1}, \beta_{3}\right)$ and $g\left(\beta_{1}, \beta_{3}\right)$ for various values of $r$ are shown in Figure 11. It is 
TABLE 2. Runoff-Sediment Data for U.S. Geological Survey Watershed 1-4815

\begin{tabular}{rrr}
\hline No. & $\begin{array}{c}\text { Runoff } x, \\
\text { cm }\end{array}$ & $\begin{array}{c}\text { Sediment Yield } y, \\
\text { metric tons }\end{array}$ \\
\hline 1 & 1.10 & 0.080 \\
2 & 2.20 & 0.130 \\
3 & 2.30 & 0.400 \\
4 & 4.00 & 0.185 \\
5 & 4.50 & 0.670 \\
6 & 5.00 & 0.680 \\
7 & 5.20 & 0.370 \\
8 & 5.30 & 0.680 \\
9 & 5.60 & 0.270 \\
10 & 5.70 & 0.300 \\
11 & 6.70 & 1.200 \\
12 & 6.80 & 0.620 \\
13 & 8.00 & 0.800 \\
14 & 8.80 & 2.200 \\
15 & 11.50 & 2.800 \\
16 & 12.00 & 2.000 \\
17 & 13.00 & 2.500 \\
18 & 14.00 & 0.550 \\
19 & 16.00 & 1.300 \\
20 & 18.00 & 9.000 \\
& $\sigma_{x}=4.78, \sigma_{y}=1.98$, and $\sigma_{x y}$ & $=6.65$ \\
& &
\end{tabular}

seen that for higher values of $r$, the region of discontinuity around the curve $\beta_{3}=\beta_{1}{ }^{2}$ becomes smaller. The $g\left(\beta_{1}, \beta_{3}\right)$ curves are hyperbolic in nature with asymptotes at the points of discontinuity and at zero. The asymptotic nature of the hyperbolae increases with the correlation coefficient $r$. For high values of $r(>0.95)$, two asymptotes (vertical and horizontal) almost completely dominate the $g\left(\beta_{1}, \beta_{3}\right)$ domain. Figures $1-10$ can be interpreted hydrologically by examining the slope of $g\left(\beta_{1}, \beta_{3}\right)$ curves. The horizontal asymptotes of these curves are unlikely to happen, since an increase of $\beta_{1}$, thus runoff, would require a decrease in $\beta_{2}$, thus sediment yield in order for $\beta_{3}$ to remain constant, an improbable event. The unique relationship between $\beta_{1}$ and $\beta_{3}$ would hold in the domain between those two curves. With the decrease of the correlation coefficient $r$, this region grows wider, and finally, when $r$ approaches zero, any value of runoff is possible for the sediment yield. This is expected, since this is the case with no correlation (see, for example, Figure 1 for $r=0.05$ ). With increase of $r$, this region narrows, and finally, when $r$ approaches one, $g\left(\beta_{1}, \beta_{3}\right)$ curve becomes rectangular. There is only one valid unique relationship between runoff and sediment yield which is for the vertical side of that rectangle (see, for example, Figure 10 for $r=0.90$ ).

\section{Stochastic Model: An Extension}

The stochastic sediment yield model derived in (26) was extended to include a simple linear relation between sediment yield and corresponding direct runoff volume. This linear relation has been noted previously [Rendon-Herrero, 1974; Singh and Chen, 1982]. The relation between $x$ and $y$ used can be expressed as

$$
\log y=\log a+b \log x
$$

The parameters $a$ and $b$ can be obtained using the least squares procedure as

$$
\begin{gathered}
\log a=\left[\left(\sum_{i=1}^{n}\left(\log x_{i}\right)^{2}\right)\left(\sum_{i=1}^{n} \log y_{i}\right)-\left(\sum_{i=1}^{n} \log x_{i}\right)\right. \\
\left.\cdot\left(\sum_{i=1}^{n} \log x_{i} \log y_{i}\right)\right]\left(n \sum_{i=1}^{n}\left(\log x_{i}\right)^{2}-\left(\sum_{i=1}^{n} \log x_{i}\right)^{2}\right)^{-1} \\
b=\left[n\left(\sum_{i=1}^{n} \log x_{i} \log y_{i}\right)-\left(\sum_{i=1}^{n} \log x_{i}\right)\left(\sum_{i=1}^{n} \log y_{i}\right)\right] \\
\cdot\left(n \sum_{i=1}^{n}\left(\log x_{i}\right)^{2}-\left(\sum_{i=1}^{n} \log x_{i}\right)^{2}\right)^{-1}
\end{gathered}
$$

The parameters $a$ and $b$ can also be computed by correlating with watershed characteristics [Singh and Chen, 1982]. An important implication of these correlations is that the contraints related to $y$, i.e., $\sigma_{y}{ }^{2}$, can be expressed in terms of $\sigma_{x}{ }^{2}$ by taking the variance of (34). Clearly, for any known value $x, y$ can be calculated from (34). The $\beta$ coefficients can then be expressed in terms of the parameters $a$ and $b$ :

$$
\beta_{3}=\frac{\beta_{1} \beta_{2}}{r}=\frac{1}{r} \beta_{1} \frac{a x^{b}}{\sigma_{y}}
$$

Simplifying,

$$
\beta_{3}=\frac{a \beta_{1}^{b+1}}{r} \frac{\sigma_{x}^{b}}{\sigma_{y}}
$$

For the application of the extended model, the following steps can be taken. (1) Assume that $x, \sigma_{x}, \sigma_{y}$, and $\sigma_{x y}$ are known. Compute $\beta_{1}$ from (27). (2) Use (35)-(36) or any other method to compute $a$ and $b$. Determine the value of $r$. Use (37) to compute $\beta_{3}$. (3) Obtain $B\left(\beta_{1}, \beta_{3}\right)$ and $g\left(\beta_{1}, \beta_{3}\right)$ from Figures $1-10$. Check whether $\beta_{1}$ and $\beta_{3}$ are in the region of validity using Figure 11. Compute $F(y \mid x)$ from (31). (4) Using (26) and tables of the normal distribution, determine the arguments of the first and second term, and finally, determine the value of sediment yield $y$.

\section{Application}

\section{Empirical Data}

For testing the model, data sets from three various sources that had long measured records of runoff discharge and equivalent sediment yield were used. Data were transformed to M-K-S units and are presented in Tables 1 and 2. The first data set was taken from the John Martin Reservoir in Colorado [Sharma, 1977]. The 24-year historical record of sediment inflow, outflow, and equivalent discharge was available at the cross section of the stream that entered the reservoir. The second date set [Haan, 1977] represented similar measurements for 21 years record at the Green River in Kentucky. The third data set [Singh and Chen, 1982] was taken from the detailed measurements on a U.S. Geological Survey watershed 1-4815 in Virginia for a series of storm events (both the runoff and sediment discharge hydrographs were available).

\section{Estimation of Parameters}

The prior information needed for application of the stochastic model in (26) are variances $\sigma_{x}{ }^{2}$ and $\sigma_{y}{ }^{2}$ and covariance $\sigma_{x y}$, which were used as the constraints or assumed to be known. In the absence of the real data, these parameters must 
TABLE 3. Values of $a$ and $b$ for Three Data Sets

\begin{tabular}{ccc}
\hline & \multicolumn{2}{c}{ Parameter } \\
\cline { 2 - 3 } Data & \multicolumn{1}{c}{$a$} & $b$ \\
\hline John Martin Reservoir & 1.90 & 0.83 \\
Green River, Kentucky & 1.57 & 0.86 \\
Watershed 1-4815 & 59.57 & 1.34 \\
\hline
\end{tabular}

be estimated by some statistical methods. For the data sample, these parameters were defined as

$$
\begin{aligned}
S_{x}^{2} & =\frac{1}{(n-1)} \sum_{i=1}^{n}\left(x_{i}-\bar{x}\right)^{2} \\
S_{y}{ }^{2} & =\frac{1}{(n-1)} \sum_{i=1}^{n}\left(y_{i}-\bar{y}\right)^{2} \\
S_{x y} & =\frac{1}{(n-1)} \sum_{i=1}^{n}\left(x_{i}-\bar{x}\right)\left(y_{i}-\bar{y}\right)
\end{aligned}
$$

where $n$ is sample size (or the number of data points available); $\bar{x}$ and $\bar{y}$ are mean values of the runoff and sediment yields, respectively; $S_{w}{ }^{2}$ is sample variance for $w$, and $S_{x y}$ is sample covariance of $x$ and $y$ (for the three data sets these are given in Tables 1 and 2). For (34), the values of the parameters $a$ and $b$ for the three data sets are given in Table 3.

\section{Prediction}

For each value of $x$ in each data set, $\beta_{1}$ and $r$ were computed. Then $\beta_{3}$ was computed from (37). Corresponding to these values, $B\left(\beta_{1}, \beta_{3}\right)$ and $g\left(\beta_{1}, \beta_{3}\right)$ were obtained from the appropriate figure (selected from Figures 1-10) or (32) and (33). By substituting into (31), $F(y \mid x)$ was calculated for each data set. Note that two stochastic models have been derived above: one in (26) or (30) and the other in (31) incorporating

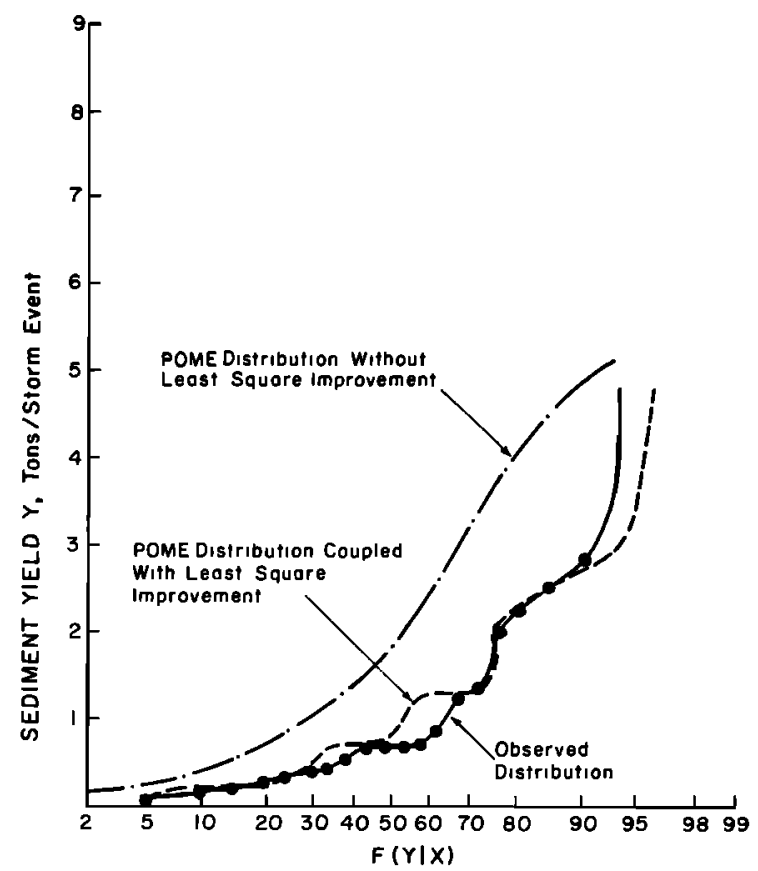

Fig. 12. Comparison of observed and computed conditional distribution of sediment yield. Two stochastic models were used to yield computed distribution: one with and the other without least squares improvement.

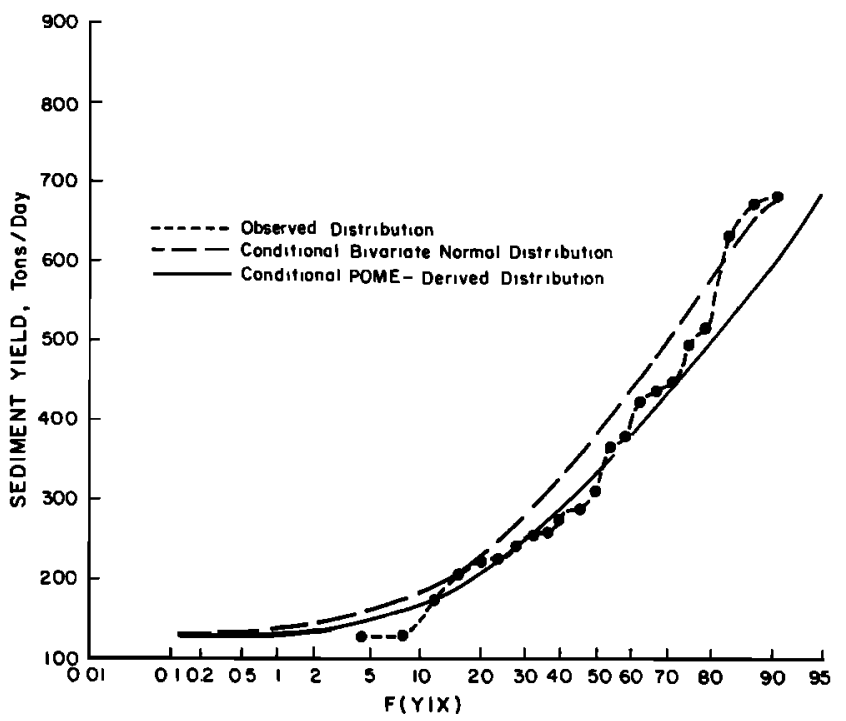

Fig. 13. Comparison of observed and computed conditional distributions of sediment yield for John Martin Reservoir. Computed distribution was obtained from the extended stochastic model as well as the conditional bivariate normal distribution.

(34). A comparison of these two models with observed distribution of sediment yield, shown in a sample Figure 12 for one data set, pointed out that the extended model in (31) was better. Consequently, this model was chosen for further analysis. The extended model was also compared with the bivariate normal distribution model. For John Martin Reservoir the extended model was found to fit better for $65 \%$ of the data in frequency distribution than the bivariate normal distribution model as shown in Figure 13. Maximum error in prediction according to Kolmogorov-Smirnov test was 0.10 , which is less than the critical value of the test statistics $(0.29)$ corresponding to $5 \%$ significance level [Yevjevich, 1972, p. 229, Table 10.3].

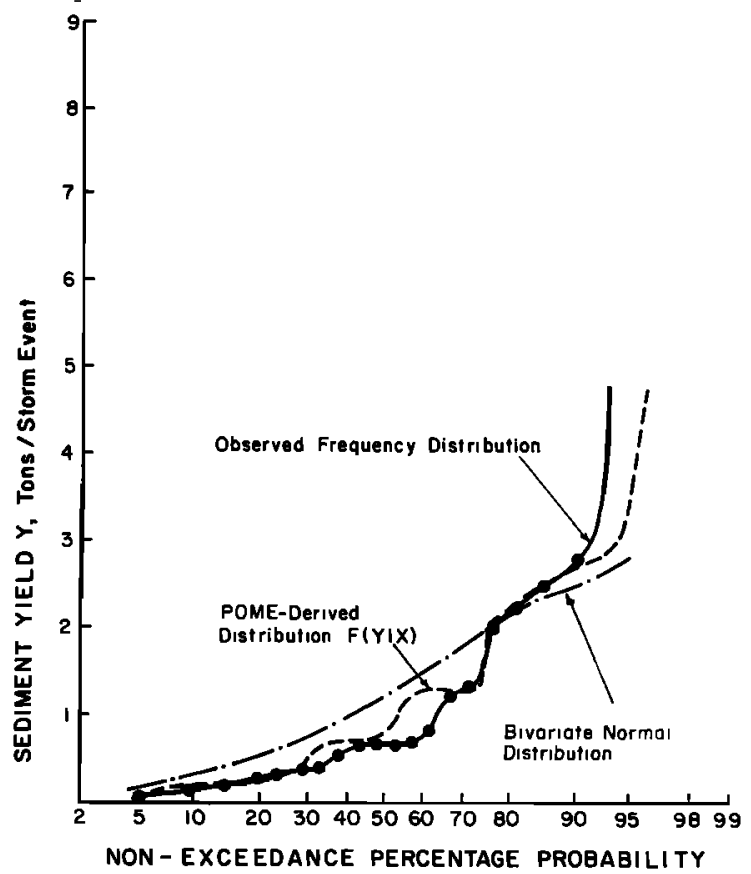

Fig. 14. Comparison of observed and computed conditional distributions of sediment yield for Watershed 1-4815. Computed distribution was obtained from the extended stochastic model as well as the conditional bivariate normal distribution. 


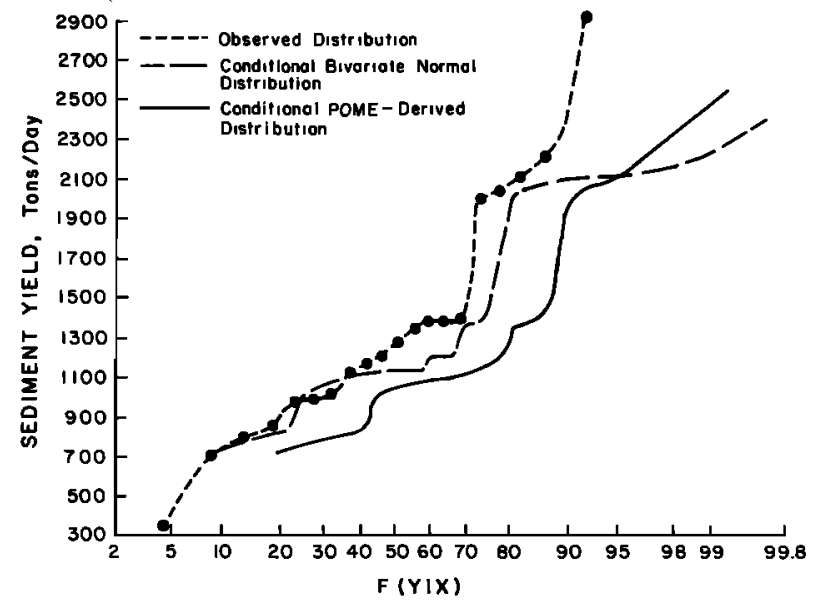

Fig. 15. Comparison of observed and computed conditional distributions of sediment yield for Green River Kentucky. Computed distribution was obtained from the extended stochastic model as well as the conditional bivariate normal distribution.

For Watershed 1-4815 the model was better for $90 \%$ of the data (Figure 14) than the bivariate normal distribution. Maximum error in the prediction was found to be the same as for the previous data set. In both cases, the data were almost equally spread from very low to very high values. For Watershed $1-4815$, the sediment yield was considered for several storms with each storm as one event. Two additional cases were considered: sediment yield during the rising hydrograph and that during the recession hydrograph. The extended model predicted the cdf accurately for the recession part, but not so well for the rising part. The predicted cdf was corrected when the lower limit of observations was greater than zero. The effect of this discrepancy is reflected in Figure 15 where the model results would be greatly improved by shifting the cdf to the left.

\section{Concluding Remarks}

The POME was used to derive minimally prejudiced probability distribution for sediment yield subject to the constraints in two-dimensional space, $\sigma_{x}{ }^{2}, \sigma_{y}{ }^{2}$, and covariance $\sigma_{x y}$; this yielded a general equation (22). By further limiting the probability space from 0 (or minimum observed value) to the observed maximum, (26) was obtained; that was applied to the sediment yield-runoff relation. On the basis of results for three different data sets (from three different environments: entrance of lake, river section, and the watershed) the following conclusions can be made.

1. The prediction was better when the available data was equally spread from very low to very high values, no matter how bad the sediment yield-runoff correlation was (e.g., John Martin Reservoir data set, Figures 12 and 13).

2. The entropy procedure worked well in cases where the data available was minimum. With more certainty, the uncertainty which entropy describes diminishes.

3. The model can be applied in practice very easily, but requires more testing to enumerate its advantages over other models.

4. Stochastic prediction model derived by POME can be extended to some other pair of variables, i.e., rainfall-runoff process (which was derived in a slightly modified way by Sonuga [1976]) or to the flood frequency analysis on which the authors are currently working.
APPENDIX

We use conditions in (3)-(6) to solve for $\lambda_{1}, \lambda_{2}, \lambda_{3}$, and $\lambda_{4}$. Using (6)

$$
\int_{-\infty}^{+\infty} \int_{-\infty}^{+\infty} \exp \left(-\lambda_{1} x^{2}-\lambda_{2} y^{2}-\lambda_{3} x y-\lambda_{4}\right) d x d y=1
$$

Separating terms containing $x$ and $y$,

$$
\begin{aligned}
& \exp \left(-\lambda_{4}\right) \int_{-\infty}^{+\infty} \exp \left(-\lambda_{1} x^{2}\right) d x \\
& \cdot \int_{-\infty}^{+\infty} \exp \left[-\lambda_{2}\left(y^{2}+\frac{\lambda_{3}}{\lambda_{2}} x y\right)\right] d y=1
\end{aligned}
$$

and using the formula

$$
G(\pi)=\int_{-\infty}^{+\infty} \exp \left(-q^{2} x^{2}\right) d x=\sqrt{\pi} / q
$$

we obtain

$$
\begin{aligned}
& \exp \left(-\lambda_{4}\right) \int_{-\infty}^{+\infty} d x \exp \left(-\lambda_{1} x^{2}\right) \\
& \cdot \int_{-\infty}^{+\infty} \exp \left[-\lambda_{2}\left\{\left(y+\frac{\lambda_{3}}{2 \lambda_{2}} x\right)^{2}-\frac{\lambda_{3}{ }^{2}}{4 \lambda_{2}{ }^{2}} x^{2}\right\}\right] d y=1 \\
& \exp \left(-\lambda_{4}\right) \int_{-\infty}^{+\infty} d x\left[\exp \left(-\lambda_{1} x^{2}+\frac{\lambda_{3}{ }^{2} x^{2}}{4 \lambda_{2}}\right)\right] \frac{\sqrt{\pi}}{\left(\lambda_{2}\right)^{1 / 2}}=1 \\
& \exp \left(-\lambda_{4}\right) \int_{-\infty}^{+\infty} d x\left\{\exp \left[-x^{2}\left(\lambda_{1}-\frac{\lambda_{3}{ }^{2}}{4 \lambda_{2}}\right)\right]\right\} \frac{\sqrt{\pi}}{\left(\lambda_{2}\right)^{1 / 2}}=1
\end{aligned}
$$

Again, using the formula $G(\pi)$ we obtain

$$
\exp \left(-\lambda_{4}\right)\left(\frac{\pi}{\lambda_{2}}\right)^{1 / 2} \frac{\sqrt{\pi}}{\left(\lambda_{1}-\frac{\lambda_{3}{ }^{2}}{4 \lambda_{2}}\right)^{1 / 2}}=1
$$

or

$$
\exp \left(\lambda_{4}\right)=\frac{2 \pi}{\left(4 \lambda_{1} \lambda_{2}-\lambda_{3}{ }^{2}\right)^{1 / 2}}
$$

Equation (A1) gives $\lambda_{4}$ as a function of $\lambda_{1}, \lambda_{2}$, and $\lambda_{3}$. In order to solve for all Lagrange multipliers, three more equations are needed. By substituting (7) into (3), and separating for $x$ and $y$,

$$
\begin{aligned}
& \sigma_{x}^{2}=\exp \left(-\lambda_{4}\right) \int_{-\infty}^{+\infty} {\left[\exp \left(-\lambda_{1} x^{2}\right)\right] x^{2} d x } \\
& \cdot \int_{-\infty}^{+\infty} \exp \left[-\lambda_{2} y^{2}-\lambda_{3} x y\right] d y
\end{aligned}
$$

The inner integral can be expanded and solved using $G(\pi)$ as

$$
\begin{aligned}
\int_{-\infty}^{+\infty} \exp \left\{-\lambda_{2}\left[\left(y+\frac{\lambda_{3}}{2 \lambda_{2}} x\right)^{2}-\frac{\lambda_{3}^{2}}{4 \lambda_{2}^{2}} x^{2}\right]\right\} d y \\
=\exp \left[\left(\frac{\lambda_{3}}{4 \lambda_{2}}\right) x^{2}\right] \frac{\sqrt{\pi}}{\left(\lambda_{2}\right)^{1 / 2}}
\end{aligned}
$$

Substituting into (A2),

$\sigma_{x}^{2}=\exp \left(-\lambda_{4}\right)\left(\frac{\pi}{\lambda_{2}}\right)^{1 / 2} \int_{-\infty}^{+\infty}\left\{\exp \left[-x^{2}\left(\lambda_{1}-\frac{\lambda_{3}{ }^{2}}{4 \lambda_{2}}\right)\right]\right\} x^{2} d x$

Replacing $\lambda_{1}-\lambda_{3}{ }^{2} / 4 \lambda_{2}=p$, we obtain

$$
\sigma_{x}^{2}=\exp \left(-\lambda_{4}\right)\left(\frac{\pi}{\lambda_{2}}\right)^{1 / 2} \int_{-\infty}^{+\infty} x^{2} \exp \left(-p x^{2}\right) d x
$$


In order to solve (A3), we use the formula [Gradshtein and Rhyzhik, 1980, equation 3.461-2]

$$
W(p)=\int_{-\infty}^{+\infty} x^{2 n} \exp \left(-p x^{2}\right) d x=\frac{(2 n-1) ! !}{(2 p)^{n}}\left(\frac{\pi}{p}\right)^{1 / 2}
$$

where $n=1, p>0$. Solving (A3),

$$
\begin{gathered}
\sigma_{x}{ }^{2}=\exp \left(-\lambda_{4}\right)\left(\frac{\pi}{\lambda_{2}}\right)^{1 / 2} \frac{1}{2\left[\lambda_{1}-\lambda_{3}{ }^{2} / 4 \lambda_{2}\right]} \frac{\sqrt{\pi}}{\left[\lambda_{1}-\lambda_{3}{ }^{2} / 4 \lambda_{2}\right]^{1 / 2}} \\
\sigma_{x}{ }^{2}=\frac{1}{\exp \left(\lambda_{4}\right)} \frac{4 \pi \lambda_{2}}{\left[4 \lambda_{1} \lambda_{2}-\lambda_{3}{ }^{2}\right]^{3 / 2}}
\end{gathered}
$$

On substituting the expression for $\exp \left(\lambda_{4}\right)$ from (A1) into (A4), the expression of $\sigma_{x}^{2}$ can be simplified to

$$
\sigma_{x}^{2}=\frac{2 \lambda_{2}}{4 \lambda_{1} \lambda_{2}-\lambda_{3}^{2}}
$$

Using a similar procedure, $\sigma_{y}{ }^{2}$ is obtained as

$$
\begin{aligned}
& \sigma_{y}{ }^{2}=\int_{-\infty}^{+\infty} \int_{-\infty}^{+\infty} y^{2} \exp \left[-\lambda_{1} x^{2}-\lambda_{2} y^{2}-\lambda_{3} x y-\lambda_{4}\right] d x d y \\
& {\sigma_{y}}^{2}=\exp \left(-\lambda_{4}\right) \int_{-\infty}^{+\infty} \exp \left(-\lambda_{2} y^{2}\right) y^{2} d y \\
& \int_{-\infty}^{+\infty} \exp \left[-\lambda_{1} x^{2}-\lambda_{3} x y\right] d x
\end{aligned}
$$

Solving inner integral using $G(\pi)$ we obtain

$$
\int_{-\infty}^{+\infty} \exp \left[-\lambda_{1} x^{2}-\lambda_{3} x y\right] d x=\exp \left(-\frac{\lambda_{3}^{2}}{4 \lambda_{1}} y^{2}\right)\left(\frac{\pi}{\lambda_{1}}\right)^{1 / 2}
$$

Plugging back into (A6) and rearranging,

$$
\sigma_{y}^{2}=\left(\frac{\pi}{\lambda_{1}}\right)^{1 / 2} \exp \left(-\lambda_{4}\right) \int_{-\infty}^{+\infty} y^{2} \exp \left(-y^{2} p\right) d y
$$

Using $W(p)$ for $n=1$,

$$
\sigma_{y}^{2}=\frac{2 \lambda_{1}}{4 \lambda_{1} \lambda_{2}-\lambda_{3}^{2}}
$$

which is the third equation connecting $\lambda_{1}, \lambda_{2}, \lambda_{3}$, and $\lambda_{4}$. The fourth equation connecting $\lambda_{i}$ can be obtained by substituting (7) into the expression for covariance in (5):

$$
\sigma_{x y}=\int_{-\infty}^{+\infty} \int_{-\infty}^{+\infty}\left[\exp \left(-\lambda_{1} x^{2}-\lambda_{2} y^{2}-\lambda_{3} x y-\lambda_{4}\right)\right] x y d x d y
$$

Separating integrals for $x$ and $y$,

$$
\begin{gathered}
\sigma_{x y}=\exp \left(-\lambda_{4}\right) \int_{-\infty}^{+\infty} x d x \exp \left(-\lambda_{1} x^{2}\right) \\
\cdot \int_{-\infty}^{+\infty}\left(\exp \left[-\lambda_{2}\left\{\left(y+\frac{\lambda_{3}}{2 \lambda_{2}} x\right)^{2}-\frac{\lambda_{3}}{4 \lambda_{2}} x^{2}\right\}\right]\right) y d y \\
\sigma_{x y}=\exp \left(-\lambda_{4}\right) \int_{-\infty}^{+\infty} x d x \exp \left[-x^{2}\left(\lambda_{1}-\frac{\lambda_{3}}{4 \lambda_{2}^{2}}\right)\right] \\
\cdot \int_{-\infty}^{+\infty}\left(\exp \left[-\lambda_{2}\left(y+\frac{\lambda_{3}}{2 \lambda_{2}} x\right)^{2}\right]\right) y d y
\end{gathered}
$$

Equation (A8) can be solved by using the substitutions

$$
\begin{aligned}
Y & =y+\frac{\lambda_{3}}{4 \lambda_{2}} x \\
d Y & =d y
\end{aligned}
$$

Then

$$
\begin{aligned}
& \sigma_{x y}=\exp \left(-\lambda_{4}\right) \int_{-\infty}^{+\infty} x d x \exp \left[-\left(\lambda_{1}-\frac{\lambda_{3}^{2}}{4 \lambda_{2}}\right) x^{2}\right] \\
& \cdot\left[\int_{-\infty}^{+\infty}\left(\exp \left(-\lambda_{2} Y^{2}\right)\right) Y d Y-\int_{-\infty}^{+\infty}\left(\exp \left(-\lambda_{2} Y^{2}\right)\right) \frac{\lambda_{3}}{2 \lambda_{2}} x d Y\right]
\end{aligned}
$$

The first integral within brackets can be solved by integration by parts and the second by using $G(\pi)$. Solving the first integral,

$$
\int_{-\infty}^{+\infty} \exp (-u) d u-\frac{\lambda_{3}}{2 \lambda_{2}} x\left(\frac{\pi}{\lambda_{2}}\right)^{1 / 2}=-\frac{\lambda_{3}}{2 \lambda_{2}} x\left(\frac{\pi}{\lambda_{2}}\right)^{1 / 2}
$$

Plugging back into (A4), we obtain

$$
-\frac{\lambda_{3}}{2 \lambda_{2}}\left(\frac{\pi}{\lambda_{2}}\right)^{1 / 2} \exp \left(-\lambda_{4}\right) \int_{-\infty}^{+\infty} x^{2} d x \exp \left[-x^{2}\left(\lambda_{1}-\frac{\lambda_{3}{ }^{2}}{4 \lambda_{2}}\right)\right]
$$

Solving the integral in the same way as (A3),

$$
-\frac{\lambda_{3}}{4 \lambda_{1} \lambda_{2}-\lambda_{3}^{2}}=\sigma_{x y}
$$

Acknowledgments. This study was supported in part by funds provided by the Geological Survey, U.S. Department of Agriculture, through the Louisiana Water Resources Research Institute, under the project, A Multivariate Stochastic Analysis of Flood Magnitude, Duration and Volume.

\section{REFERENCES}

Agricultural Research Service, Present and prospective technology for predicting sediment yields and sources, paper presented at Proceedings, Sediment-Yield Workshop, U.S. Dep. Agric. Sediment. Lab., Oxford, Miss., 1975.

Alonso, C. V., Selecting a formula to estimate sediment transport capacity in non-vegetated channels, CREAMS: A Field Scale Model for Chemicals, Runoff and Erosion from Agricultural Management Systems, conservation research report, U.S. Dep. of Agric., Washington, D. C., 1980.

American Society of Civil Engineers, Sediment sources and sediment yields, J. Hydraul. Div. Am. Soc. Civ. Eng., 96(HY6), 1283-1329, 1970.

Amorocho, J., and B. Espildora, Entropy in the assessment of uncertainty in hydrologic systems and models, Water Resour. Res., 9(6), $1511-1522,1973$.

Borah, D. K., The dynamic simulation of water and sediment in watersheds, Ph.D. dissertation, 224 pp., The Univ. of Miss., Mississippi, 1979.

Caroni, E., V. P. Singh, and L. Ubertini, Rainfall-runoff sediment yield relation by stochastic modeling, Hydrol. Sci. J., 29(2/6), 203$218,1984$.

Curtis, D. C., A deterministic urban storm water and sediment discharge model, paper presented at Proceedings, National Symposium on Urban Hydrology, Hydraulics, and Sediment Control, Univ. of Ky., Lexington, 1976.

Foster, G. R., Modeling the erosion process, in Hydrologic Modeling of Small Watersheds, edited by C. T. Haan, H. P. Johnson, and D. L. Brakensick, American Society of Agricultural Engineers, St. Joseph, Mich., 1981.

Foster, G. R., and L. D. Meyer, A closed form soil erosion evaluation for upland areas, in Sedimentation, edited by H. W. Shen, pp. 12.112.19, Water Resources Publications, Fort Collins, Colo., 1972.

Foster, G. R., and L. D. Meyer, Mathematical simulation of upland 
erosion by fundamental erosion mechanics, Present and Prospective Technology for Predicting Sediment Yields and Sources, Rep. ARS-S-40, pp. 190-207, Agric. Res. Serv., U.S. Dep. of Agric., Washington, D. C., 1975.

Gradshtein, I. S., and I. M. Rhyzhik, Tables of Integrals, Series and Products, Academic Orlando, Fla., 1980.

Haan, C. T., Statistical Methods in Hydrology, The Iowa University Press, Ames, 1977.

Jaynes, E. T., Information theory and statistical mechanics, I, Phys. Rev., 106, 620-630, 1957a.

Jaynes, E. T., Information theory and statistical mechanics, II, Phys. Rev., 108, 171-191, $1957 b$.

Jaynes, E. T., Where do we stand on maximum entropy, in Jaynes' Papers on Probability, Statistics and Statistical Physics, edited by R. D. Rosencratz, D. Reidel, Hingham, Mass., 1983.

Jones, D. S., Elementary Information Theory, Clarendon, Oxford, 1979.

Knisel, W. G., Jr., Erosion and sediment yield Models-An overview, paper presented at Proceedings, ASCE Symposium on Watershed Management, Am. Soc. Civ. Eng., Boise, Idaho, $1980 a$.

Knisel, W. G. (Ed.), A field-scale model for chemicals runoff and erosion from agricultural systems, Conserv. Res. Rep., 26, 840 pp., U.S. Dep. of Agric., Washington, D. C., $1980 b$.

Lane, L. J., and K. G. Renard, Evaluation of a basinwide stochastic model for ephemeral runoff, Trans. $A S A E, 15(1), 280-283,1972$.

$\mathrm{Li}, \mathbf{R}$. M., Water and sediment routing from watersheds, in Modeling of Rivers, edited by W. Shen, Wiley-Interscience, New York, 1979.

Li, R. M., D. B. Simons, and M. A. Stevens, Review of literature: Cooperative study of development of models for predicting sediment yield from small watersheds, Rep. CER72-73 RML-DBS-MAS 14, Civ. Eng. Dep., Colo. State Univ., Fort Collins, 1973.

Renard, K. G., Past, present and future water resources research in arid and semi-arid areas of the Southwestern United States, paper at Proceedings, Hydrologic Symposium, Austr. Inst. of Eng., Canberra, 1977.

Renard, K. G., Estimating erosion and sediment yield from range land, paper presented at Proceedings, ASCE Symposium on Watershed Management, Am. Soc. Civ. Eng., Boise, Idaho, 1980.

Rendon-Herrero, O., Estimation of washload produced on certain small watersheds, J. Hydraul. Div. Am. Soc. Civ. Eng., 100(HY7), 835-840, 1974.

Rendon-Herrero, O., Unit sediment graph, Water Resour. Res., 14(5), 889-901, 1978.

Rendon-Herrero, O., V. P. Singh, and V. T. Chen, ER-ES watershed relationship, in Proceedings, International Symposium on Water Resources Systems, vol. 1, pp. II-8-41-II-8-47, University of Roorkee, Roorkee, India, 1980.

Reza, F. M., An Introduction to Information Theory, McGraw-Hill, New York, 1961.

Ross, B. B., V. O. Shanholtz, and D. N. Contractor, A spatially responsive hydrologic model to predict erosion and sediment transport, Water Resour. Bull., 16(3), 338-345, 1980.

Shannon, C. E., and W. Weaver, The Mathematical Theory of Communication, University of Illinois Press, Urbana, 1949.

Sharma, T. C., A discrete dynamic model of watershed sediment yield, Ph.D. thesis, Univ. of Guelph, Can., 1977.

Singh, V. P., Analytical solutions of kinematic equations for erosion on a plane, II, Rainfall of finite duration, Adv. Water Resour., 6 , 2-10, 1983.
Singh, V. P., Hydrologic Systems, vol. 2, Watershed Modeling, Prentice-Hall, Englewood Cliffs, N. J., 1986.

Singh, V. P., and V. J. Chen, On the relation between sediment yield and runoff volume, in Modeling Components of Hydrologic Cycle, edited by V. P. Singh, pp. 555-570, Water Resources Publications, Littleton, Colo., 1982.

Singh, V. P., and S. N. Prasad, A hydrodynamic model of sediment transport in rill flows, IAHS Publ., 137, 293-301, 1982.

Singh, V. P., and R. R. Regl, Analytical solutions of kinematic equations for erosion on a plane, I, Rainfall of indefinite duration, $A d v$. Water Resour., 6, 88-95, 1983.

Singh, V. P., A. Baniukiewicz, and V. J. Chen, An instantaneous unit sediment graph study for small upland water sheds, in Modeling Components of Hydrologic Cycle, edited by V. P. Singh, pp. 539554, Water Resources Publications, Littleton, Colo., 1982.

Singh, V. P., K. Singh, and A. K. Rajagopal, Application of the principle of maximum entropy (POME) to hydrologic frequency analysis, completion report, 144 pp., La. Water Resour. Res. Inst., La. State Univ., Baton Rouge, 1985.

Smith, R. E., Simulating erosion dynamics with a deterministic distributed watershed model, paper presented at Proceedings, Third Federal Interagency Sedimentation Conference, U.S. Dep. of Agric., Denver, Colo., March 22-25, 1976.

Sonuga, J. O., Principle of maximum entropy in hydrologic frequency analysis, J. Hydrol., 17(3), 177-219, 1972.

Sonuga, J. O., Entropy principle applied to the rainfall-runoff process, J. Hydrol., 30, 81-94, 1976.

Wehrl, A., General properties of entropy, Rev. Mod. Phys., 50(2), 221260, 1978.

Williams, J. R., A sediment yield routing model, in Proceedings of the Specialty Conference on Verification of Mathematical and Physical Models in Hydraulic Engineering, pp. 662-670, American Society of Civil Engineers, New York, 1978.

Williams, J. R., Mathematical modeling of watershed sediment yield, in Modeling Components of Hydrologic Cycle, edited by V. P. Singh, pp. 499-514, Water Resources Publications, Littleton, Colo., 1982.

Woolhiser, D. A., and P. H. Blinco, Watershed sediment yield-A stochastic approach, Present and Prospective Technology for Predicting Sediment Yields and Sources, Rep. USDA-ARS-S-40, pp. 264-773, Agric. Res. Serv., U.S. Dep. Agric., Washington, D. C., 1975.

Woolhiser, D. A., and K. G. Renard, Stochastic aspects of watershed sediment yield, in Application of Stochastic Processes in Sediment Transport, edited by $\mathbf{H}$. W. Shen and H. Hikkavan, Water Resources Publications, Littleton, Colo., 1980.

Woolhiser, D. A., and P. Todorovic, A stochastic model of sediment yield for ephemeral streams, Misc. Publ. U.S. Dep. of Agric., 1275, 232-246, 1974.

Yevjevich, V., Probability and Statistics in Hydrology, Water Research Publications, Fort Collins, Colorado, 1972.

P. F. Krstanovic and V. P. Singh, Department of Civil Engineering, Louisiana State University, Baton Rouge, LA 70803.

(Received December 12, 1985; revised November 10, 1986; accepted November $12,1986$. 